\title{
USO DE REGULADOR DE CRESCIMENTO EM CULTIVARES DE FEIJÃO DE INVERNO ${ }^{1}$
}

\begin{abstract}
Fabiana Lima Abrantes², Marco Eustáquio de Sá2, Lilian Christian Domingues de Souza ${ }^{2}$, Mariana Pina da Silva ${ }^{2}$, Helena Masumi Simidu ${ }^{2}$, Marcelo Andreotti ${ }^{2}$, Salatiér Buzetti ${ }^{2}$,Walter Veriano Valério Filho ${ }^{2}$, Natália Arruda $^{2}$
\end{abstract}

\section{ABSTRACT \\ PLANT GROWTH STIMULANT APPLICATION ON WINTER COMMON BEAN CULTIVARS}

The use of plant growth stimulants for increasing crop yield has recently called the attention of researchers, but some results have proved contradictory. For that reason, the objective of this study was to evaluate the effects of plant growth stimulant application on components and grains yield of two winter common bean cultivars under Brazilian savannah conditions. The experiment was conducted during the 2007 fall-winter season, at the Unesp experimental farm, Ilha Solteira campus, in Selvíria, Mato Grosso do Sul State, Brazil. The experimental design was randomized blocks, in a strips scheme, with four replications. The treatments consisted of a combination of five plant growth stimulant doses ( $0 \mathrm{~L} \mathrm{ha}^{-1} ; 0.5 \mathrm{~L} \mathrm{ha}^{-1}$; $1.0 \mathrm{~L} \mathrm{ha}^{-1} ; 1.5 \mathrm{~L} \mathrm{ha}^{-1}$; and $\left.2.0 \mathrm{Lha}^{-1}\right)$, composed of three vegetable hormones (kinetin, gibberellic acid, and indolbutyric acid), in two application periods: at the vegetative stage (V4) and at the reproductive stage (R5). Vegetative characteristics such as plant height, first pod insertion height, number of grains per pod, and weight of 100 grains were not affected by the product application. However, its application at the reproductive stage (R5) increased the number of grains per plant and grain yield of the Carioca Precoce and IAC Apuã bean cultivars. For that increase, $2 \mathrm{~L} \mathrm{ha}^{-1}$ was the best plant growth stimulant dose.

KEY-WORDS: Phaseolus vulgaris; yield components; application period.

\section{INTRODUÇÃO}

O cultivo de feijão, no Brasil, ocorre, praticamente, durante todo o ano. É cultivado na época "das águas", "da seca" e "de inverno". De acordo com Maeda \& Mendonça (1990), o cultivo em várias épocas do ano se deve ao fato de a cultura não apresentar sensibilidade ao fotoperíodo. Entretanto, é necessário que não ocorram limitações de temperatura e disponibilidade hídrica.

\section{RESUMO}

A aplicação de reguladores vegetais, com a finalidade de aumentar a produtividade das culturas, tem merecido, nos últimos anos, grande atenção de pesquisadores. No entanto, alguns resultados têm se mostrado contraditórios. Em face disto, este estudo teve como objetivo verificar os efeitos da aplicação de regulador vegetal sobre os componentes da produção e a produtividade de grãos de duas cultivares de feijão de inverno, em condições de Cerrado. O experimento foi realizado no outono-inverno de 2007, na Fazenda Experimental da Unesp, Campus de Ilha Solteira, localizada no município de Selvíria (MS). O delineamento experimental foi o de blocos casualizados, no esquema em faixas, com quatro repetições. Os tratamentos constituíram-se da combinação de cinco doses do regulador vegetal $\left(0 \mathrm{~L} \mathrm{ha}^{-1} ; 0,5 \mathrm{~L} \mathrm{ha}^{-1} ; 1,0 \mathrm{~L} \mathrm{ha}^{-1} ; 1,5 \mathrm{~L} \mathrm{ha}^{-1}\right.$; e 2,0 $\left.\mathrm{L} \mathrm{ha}^{-1}\right)$, que é composto por três hormônios vegetais (cinetina, ácido giberélico e ácido indolbutírico), em duas épocas de aplicação: no estádio vegetativo (V4) e reprodutivo (R5). Características vegetativas como altura das plantas de feijão, altura de inserção da primeira vagem, número de grãos por vagem e massa de 100 grãos não foram afetadas pela aplicação do produto. No entanto, sua aplicação no estádio reprodutivo (R5) aumentou o número de grãos por planta e a produtividade de grãos das cultivares de feijoeiro Carioca Precoce e IAC Apuã. Para este aumento, a melhor dose foi $2 \mathrm{~L} \mathrm{ha}^{-1}$ do regulador vegetal.

PALAVRAS-CHAVE: Phaseolus vulgaris; componentes da produção; época de aplicação.

Com o intuito de se elevarem os níveis de produtividade do feijão (Phaseolus vulgaris L.), novas tecnologias vêm sendo desenvolvidas e testadas. Neste sentido, pesquisas com o uso de reguladores de crescimento, associados ou não a adubações, têm sido cada vez mais comuns (Lana et al. 2009), objetivando modificar o desenvolvimento das plantas, com reflexos na produtividade (Dourado Neto et al. 2004).

Os órgãos das plantas são alterados morfologicamente pela aplicação de bioestimulantes, de forma

1. Trabalho recebido em nov./2009 e aceito para publicação em mar./2011 (n registro: PAT 8287/ DOI: 10.5216/pat.v41i2.8287).

2. Universidade Estadual Paulista "Júlio de Mesquita Filho", Faculdade de Engenharia de Ilha Solteira, Ilha Solteira, SP, Brasil. E-mails: fabianaabrantes@hotmail.com,marcosa@agr.feis.unesp.br, lilianagronomia90@hotmail.com,mari_agro@hotmail.com, helena_simidu@hotmail.com,dreotti@agr.feis.unesp.br, sbuzetti@agr.feis.unesp.br,wvvf@mat.feis.unesp.br, nathy.a@hotmail.com. 
que o crescimento e o desenvolvimento são promovidos ou inibidos, o que influencia ou modifica os processos fisiológicos e exerce controle da atividade meristemática (Weaver 1972).

Acredita-se que o regulador vegetal, composto por ácido indolbutírico, cinetina e ácido giberélico, pode, em função de sua composição, concentração e proporção das substâncias, incrementar o crescimento e desenvolvimento vegetal, estimulando a divisão celular e podendo, também, aumentar a absorção de água e nutrientes pelas plantas (Vieira \& Castro 2002).

Os biorreguladores vegetais são substâncias sintéticas que, aplicadas exogenamente, possuem ações similares às dos grupos de reguladores vegetais naturalmente produzidos pelas plantas (citocininas, giberelinas, auxina e etileno) (Vieira \& Castro 2002). Segundo Casillas et al. (1986), estas substâncias são eficientes, quando aplicadas em baixas doses, favorecendo o bom desempenho dos processos vitais da planta e permitindo a obtenção de melhores colheitas, além de garantir rendimentos satisfatórios em condições ambientais adversas. Alguns autores têm observado resultados favoráveis ao aumento da produtividade da cultura de feijão (Alleoni et al. 2000, Vieira \& Castro 2001, Vieira \& Castro 2004).

$\mathrm{O}$ bioestimulante pode ser utilizado tanto no tratamento de sementes como no sulco de semeadura e/ou em pulverizações foliares. Resultados positivos têm sido verificados em várias culturas, como feijão (Alleoni et al. 2000, Cobucci et al. 2005), soja (Bertolin et al. 2010), mamona (Albuquerque et al. 2004) e algodão (Lima et al. 2006), dentre outras.

Na cultura da soja, Bertolin et al. (2010) observaram que o Stimulate ${ }^{\circledR}$ proporcionou incremento no número de vagens por planta e na produtividade de grãos de soja, tanto em aplicação via sementes quanto via foliar. Na mesma cultura, Dario et al. (2005) observaram que a utilização do Stimulate ${ }^{\circledR}$ no tratamento de sementes, em pulverização dirigida na linha de sementes e em pulverização foliar, não apresentou diferença significativa sobre o número de vagens por plantas e o rendimento de grãos de soja.

Considerando-se que a aplicação de produtos contendo cinetina, ácido giberélico e ácido indolbutírico pode melhorar o desempenho das plantas, o presente trabalho objetivou verificar os efeitos da aplicação do regulador vegetal sobre os componentes da produção e a produtividade de grãos de duas cultivares de feijão de inverno, em condições de Cerrado.

\section{MATERIAL E MÉTODOS}

O trabalho foi realizado no outono-inverno de 2007, com uso de irrigação por pivô central, na Fazenda de Ensino, Pesquisa e Extensão da Faculdade de Engenharia, Campus de Ilha Solteira (Unesp), localizada em Selvíria, MS $\left(20^{\circ} 22^{\prime}\right.$ S , $51^{\circ} 22^{\prime} \mathrm{W}$ e altitude de $335 \mathrm{~m}$ ).

O solo da área experimental foi classificado como Latossolo Vermelho distrófico típico (Embrapa 1999). Antes da instalação do experimento, foram coletadas amostras de solo da área experimental, para determinação dos atributos químicos, na camada de 0-0,20 m, de acordo com método proposto por Raij et al. (2001), cujos resultados foram: $25,4 \mathrm{~g} \mathrm{dm}^{-3}$ de matéria orgânica; $\mathrm{pH}\left(\mathrm{CaCl}_{2}\right) 4,7 ; 17,1 \mathrm{mg} \mathrm{dm}^{-3}$ de P; 5,9 $\mathrm{mmol}_{\mathrm{c}} \mathrm{dm}^{-3} \mathrm{de} \mathrm{K} ; 19 \mathrm{mmol}_{\mathrm{c}} \mathrm{dm}^{-3} \mathrm{de} \mathrm{Ca}$;

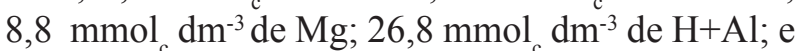
$55,7 \%$ de saturação por bases (V\%).

A média da precipitação pluvial, temperaturas máxima, mínima e média e da umidade relativa do ar, durante a condução do experimento, foram $0,81 \mathrm{~mm}$; $29,4^{\circ} \mathrm{C} ; 14,7^{\circ} \mathrm{C} ; 21,5^{\circ} \mathrm{C} ;$ e $65,2 \%$, respectivamente, e a irrigação diária foi de $5 \mathrm{~mm}$, por meio de pivô central.

O delineamento experimental utilizado foi o de blocos casualizados, no esquema em faixas, com quatro repetições. Os tratamentos foram constituídos pela combinação de cinco doses do regulador vegetal $\left(0 \mathrm{~L} \mathrm{ha}^{-1} ; 0,5 \mathrm{~L} \mathrm{ha}^{-1} ; 1,0 \mathrm{~L} \mathrm{ha}^{-1} ; 1,5 \mathrm{~L} \mathrm{ha}^{-1}\right.$; e $2,0 \mathrm{~L} \mathrm{ha}^{-1}$ ), que é composto por $0,009 \%$ de cinetina (citocinina), 0,005\% de ácido giberélico (giberelina) e $0,005 \%$ de ácido indolbutírico (comercializado como Stimulate ${ }^{\circledR}$ ), duas cultivares (Carioca Precoce e IAC Apuã) e duas épocas de aplicação (estádio V4 e R5).

No estádio V4, a aplicação ocorreu aos 29 dias após a emergência (DAE), para as duas cultivares, e, no estádio R5, aos 40 DAE, para a cultivar Carioca Precoce (tipo I), e aos 46 DAE, para a cultivar IAC Apuã (tipo II).

A distribuição das doses foi realizada em aplicação única, em cada estádio fenológico, com o auxílio de um pulverizador costal de 20 litros, aplicando-se volume de calda equivalente a $300 \mathrm{~L} \mathrm{ha}^{-1}$, utilizando-se um bico cônico, e as pulverizações ocorreram sempre no período da manhã.

As parcelas constituíram-se de cinco linhas de 5 metros de comprimento, com espaçamento de $0,45 \mathrm{~m}$, sendo consideradas como área útil as três linhas centrais, desprezando-se $0,5 \mathrm{~m}$ em cada extremidade das linhas. 
O solo foi preparado com uma aração e duas gradagens e a semeadura realizada manualmente, em 25/05/2007, em sulcos de, aproximadamente, $0,05 \mathrm{~m}$ de profundidade, distribuindo-se, em média, 15 sementes $\mathrm{m}^{-1}$, para cada uma das cultivares, visando-se a obter estande de 12 plantas $\mathrm{m}^{-1}$ e população de 266.666 plantas $a^{-1}$. A emergência das plântulas ocorreu em 03/06/2007.

A adubação de semeadura e cobertura foi a mesma em todos os tratamentos. Na semeadura, foram aplicados $250 \mathrm{~kg} \mathrm{ha}^{-1}$ da fórmula 08-28-16 e, em cobertura, realizada aos 31 dias após a emergência (DAE) das plântulas, aplicaram-se, manualmente, $40 \mathrm{~kg} \mathrm{ha}^{-1}$ de N, utilizando-se, como fonte, ureia. A adubação química foi realizada levando-se em consideração os resultados da caracterização química do solo e as recomendações de Ambrosano et al. (1997).

O controle das plantas daninhas foi efetuado mediante capina manual, sempre que necessário. Para controle das pragas, foram utilizados Parathion methil (300 g i.a ha-1), Methamidophos (600 g i.a ha-1), Triazofos + Deltametrina $\left(122,5 \mathrm{~g}\right.$ i.a ha ${ }^{-1}+0,35 \mathrm{~g}$ i.a ha-1) e isca formicida à base de Sulfluramida, distribuindo-se, aproximadamente, $0,024 \mathrm{~g}$ i.a m${ }^{-2}$ de terra solta do formigueiro, e, para o controle de doenças, utilizou-se o fungicida Mancozeb (1.600 g i.a ha-1).

A colheita foi realizada quando cada cultivar atingiu o estádio R9, caracterizando sua maturidade, o que ocorreu aos 87 DAE (29/08/2007), para a cultivar Carioca Precoce, e aos 92 DAE (03/09/2007), para a IAC Apuã. Foi realizada colheita manual em duas linhas de $4 \mathrm{~m}$ de comprimento, na área útil de cada parcela.

No momento da colheita, foram realizadas as contagens das plantas das duas linhas colhidas, cujos valores foram utilizados para a obtenção do número de plantas finais (população final de plantas), correspondente a um hectare. Com esta contagem, verificou-se que a população final foi de 186.500 e 203.292 plantas, respectivamente, para as cultivares Carioca Precoce e IAC Apuã.

Nesta ocasião, ainda foram coletadas 20 plantas por parcela (terceira linha da área útil), sendo identificadas e levadas ao laboratório para efetuar as avaliações de número de vagens/planta; número médio de grãos/vagem, número médio de grãos/planta e massa de 100 grãos, que foi determinada através da coleta ao acaso e pesagem de duas amostras de 100 grãos por parcela, as quais tiveram os dados corrigidos para umidade de 13\% (base úmida). Das 20 plantas coletadas anteriormente, foram separadas 10 plantas ao acaso, para avaliação da altura de plantas e altura de inserção da primeira vagem. Após a colheita manual, as plantas foram levadas para secagem a pleno sol e submetidas a trilhagem mecânica. Posteriormente, foi determinada a massa dos grãos colhidos e a umidade corrigida para 13\% (base úmida), sendo os dados transformados para $\mathrm{kg} \mathrm{ha}^{-1}$.

Os dados obtidos foram submetidos a análise de variância. As médias referentes às cultivares e épocas de aplicação do regulador vegetal foram comparadas pelo teste Tukey (5\%), enquanto os efeitos das doses do regulador vegetal foram avaliados pela análise de regressão, adotando-se, como critério para escolha do modelo, a magnitude dos coeficientes de regressão significativos a 5\%.

\section{RESULTADOS E DISCUSSÃO}

Para altura da planta e inserção da primeira vagem, ocorreram diferenças significativas apenas entre as cultivares (Tabela 1). Estas diferenças, provavelmente, resultaram das características inerentes a cada cultivar, pois a IAC Apuã caracteriza-se por

Tabela 1. Médias de altura de plantas e altura de inserção da primeira vagem de feijoeiro, em função de cultivares, doses e épocas de aplicação de regulador vegetal (Selvíria, MS, 2007).

\begin{tabular}{|c|c|c|}
\hline Tratamentos & $\begin{array}{c}\text { Altura de } \\
\text { plantas }(\mathrm{cm})\end{array}$ & $\begin{array}{l}\text { Altura de inserção } \\
\text { da } 1^{\mathrm{a}} \text { vagem }(\mathrm{cm})\end{array}$ \\
\hline \multicolumn{3}{|l|}{ Cultivares } \\
\hline IAC Apuã & $64,0 \mathrm{a}$ & $8,2 \mathrm{a}$ \\
\hline Carioca Precoce & $33,2 \mathrm{~b}$ & $4,3 \mathrm{~b}$ \\
\hline \multicolumn{3}{|l|}{$\operatorname{Doses}\left(L h a^{-1}\right)$} \\
\hline 0,0 & 47,5 & 6,5 \\
\hline 0,5 & 51,0 & 6,5 \\
\hline 1,0 & 48,0 & 6,1 \\
\hline 1,5 & 48,5 & 6,1 \\
\hline 2,0 & 47,7 & 6,0 \\
\hline \multicolumn{3}{|l|}{ Época } \\
\hline Vegetativa (29 DAE) & $49,4 \mathrm{a}$ & $6,3 \mathrm{a}$ \\
\hline Reprodutiva (R5) & $47,7 \mathrm{a}$ & $6,2 \mathrm{a}$ \\
\hline \multicolumn{3}{|c|}{ Valores de F } \\
\hline Cultivares & $109,48 * *$ & $509,69 * *$ \\
\hline Doses & $1,06^{\mathrm{ns}}$ & $2,88^{\mathrm{ns}}$ \\
\hline Épocas & $1,95^{\mathrm{ns}}$ & $0,64^{\mathrm{ns}}$ \\
\hline Doses x Épocas & $1,56^{\mathrm{ns}}$ & $1,00^{\mathrm{ns}}$ \\
\hline Cultivares x Doses & $0,23^{\mathrm{ns}}$ & $2,08^{\mathrm{ns}}$ \\
\hline Cultivares x Épocas & $0,06^{\mathrm{ns}}$ & $2,01^{\mathrm{ns}}$ \\
\hline
\end{tabular}

Médias seguidas pela mesma letra, na coluna, não diferem entre si, pelo teste Tukey, a $5 \%$. ${ }^{\text {ns }}$ Não significativo. $*$ e $* *$ Significativo a $5 \%$ e $1 \%$, respectivamente, pelo teste $\mathrm{F}$. 
plantas de crescimento indeterminado (Tipo II) e a Carioca Precoce por plantas de crescimento determinado (Tipo I).

Observando-se o efeito da época de aplicação do produto (Tabela 1), verifica-se que, embora não tenham ocorrido diferenças significativas entre as épocas, a aplicação no estádio vegetativo proporcionou maior altura de plantas e de inserção da primeira vagem. Isto pode ter ocorrido porque, na fase vegetativa, a planta deve possuir maior quantidade de regulador de crescimento do que na fase reprodutiva e, com a aplicação das doses no estádio vegetativo, aumentou-se a quantidade destes reguladores nas plantas, fazendo com que estas tivessem crescimento vegetativo maior, pois, de acordo com Leite et al. (2003), quando o ácido giberélico é aplicado antes do florescimento, o mesmo induz a um crescimento vegetativo intenso, em diversas culturas, o qual é maior do que o necessário para a máxima produtividade, e, neste caso, nutrientes e fotossintetizados são direcionados ao crescimento vegetativo, em detrimento ao desenvolvimento de estruturas reprodutivas.

Resultados diferentes foram encontrados por Castro et al. (2004), que observaram redução da altura das plantas uma semana após a aplicação de $3,0 \mathrm{~mL} \mathrm{~L}^{-1}$ de Stimulate $^{\circledR}$ e no tratamento de sementes com $2,7 \mathrm{~mL} / 0,5 \mathrm{~kg}$ de sementes. No entanto, quatro semanas após a pulverização, o efeito desapareceu e prevaleceu apenas o efeito do tratamento de sementes na redução da altura de plantas.

Para o número de vagens por planta, não ocorreram diferenças significativas entre cultivares e épocas de aplicação do regulador vegetal, avaliadas como fator isolado, mas, nas interações doses $\mathrm{x}$ cultivares e cultivares $\mathrm{x}$ épocas, foi possível observar diferenças significativas (Tabela 2).

Com o desdobramento da interação doses $\mathrm{x}$ cultivares, foi possível constatar aumento linear do número de vagens planta ${ }^{-1}$, com as doses de bioestimulate aplicadas (Figura 1) para a cultivar IAC Apuã, entretanto, o mesmo não foi observado para a cultivar Carioca Precoce.

No desdobramento da interação significativa cultivares x épocas (Tabela 3 ), para o número de vagens por planta, verificaram-se diferenças significativas entre as cultivares, na aplicação realizada no estádio reprodutivo (R5), e, dentro das cultivares, a diferença foi apenas para a IAC Apuã, a qual alcançou o maior número de vagens por planta, com a aplicação do regulador em R5. O fato de a cultivar IAC Apuã ter apresentado maior número de vagens por planta pode, também, ter ocorrido em razão da capacidade de compensação, devido à redução de estande, característica apresentada por plantas das cultivares de feijão do tipo II (Fancelli \& Dourado Neto 2007).

Tabela 2. Médias para número de vagens por planta (NVP), número de grãos por vagem (NGV), número de grãos por planta (NGP), massa de 100 grãos (MCG) e produtividade de grãos de feijoeiro (PROD), em função de cultivares, doses e épocas de aplicação de regulador vegetal (Selvíria, MS, 2007).

\begin{tabular}{|c|c|c|c|c|c|}
\hline Causas de Variação & NVP & NGV & NGP & MCG (g) & PROD $\left(\mathrm{kg} \mathrm{ha}^{-1}\right)$ \\
\hline $\begin{array}{l}\text { Cultivares } \\
\text { IAC Apuã } \\
\text { Carioca Precoce }\end{array}$ & $\begin{array}{l}10,8 \\
10,6 \\
\end{array}$ & $\begin{array}{l}3,9 \mathrm{~b} \\
4,6 \mathrm{a}\end{array}$ & $\begin{array}{l}43,0 \mathrm{a} \\
49,4 \mathrm{a}\end{array}$ & $\begin{array}{l}22,2 \mathrm{~b} \\
23,4 \mathrm{a}\end{array}$ & $\begin{array}{l}1.771 \mathrm{~b} \\
2.304 \mathrm{a}\end{array}$ \\
\hline $\begin{array}{l}\text { Doses }\left(L h a^{-1}\right) \\
0,0 \\
0,5 \\
1,0 \\
1,5 \\
2,0\end{array}$ & $\begin{array}{r}9,7 \\
10,2 \\
10,3 \\
11,3 \\
12,1 \\
\end{array}$ & $\begin{array}{l}4,2 \\
4,2 \\
4,3 \\
4,2 \\
4,5 \\
\end{array}$ & $\begin{array}{l}41,0 \\
43,1 \\
44,3 \\
47,9 \\
54,8 \\
\end{array}$ & $\begin{array}{l}22,6 \\
23,3 \\
22,7 \\
22,5 \\
22,9 \\
\end{array}$ & $\begin{array}{l}1.723 \\
1.974 \\
1.982 \\
2.095 \\
2.414 \\
\end{array}$ \\
\hline $\begin{array}{l}\text { Época } \\
\text { Vegetativa (V4) } \\
\text { Reprodutiva (R5) }\end{array}$ & $\begin{array}{l}10,5 \\
10,9 \\
\end{array}$ & $\begin{array}{l}4,2 \mathrm{a} \\
4,4 \mathrm{a} \\
\end{array}$ & $\begin{array}{l}44,0 \mathrm{~b} \\
48,4 \mathrm{a} \\
\end{array}$ & $\begin{array}{l}22,7 \mathrm{a} \\
22,9 \mathrm{a} \\
\end{array}$ & $\begin{array}{l}1.897 \mathrm{~b} \\
2.719 \mathrm{a} \\
\end{array}$ \\
\hline \multicolumn{6}{|c|}{ Valores de F } \\
\hline $\begin{array}{l}\text { Cultivares } \\
\text { Doses } \\
\text { Épocas } \\
\text { Doses x Épocas } \\
\text { Cultivares x Doses } \\
\text { Cultivares x Épocas }\end{array}$ & $\begin{array}{c}0,06^{\mathrm{ns}} \\
24,42^{* *} \\
5,63^{\mathrm{ns}} \\
3,39^{\mathrm{ns}} \\
13,13^{*} \\
24,79^{* *} \\
\end{array}$ & $\begin{array}{c}30,75^{* *} \\
1,57^{\mathrm{ns}} \\
5,46^{\mathrm{ns}} \\
0,45^{\mathrm{ns}} \\
0,30^{\mathrm{ns}} \\
0,20^{\mathrm{ns}} \\
\end{array}$ & $\begin{array}{r}1,58^{\text {ns }} \\
10,62^{*} \\
8,53^{*} \\
1,83^{\text {ns }} \\
3,02^{\text {ns }} \\
3,13^{\text {ns }} \\
\end{array}$ & $\begin{array}{l}6,91^{*} \\
2,26^{\text {ns }} \\
1,45^{\text {ns }} \\
0,89^{\text {ns }} \\
1,65^{\text {ns }} \\
1,53^{\text {ns }}\end{array}$ & $\begin{array}{r}6,42^{*} \\
7,33^{*} \\
11,61^{*} \\
0,95^{\text {ns }} \\
0,92^{\text {ns }} \\
0,04^{\text {ns }} \\
\end{array}$ \\
\hline
\end{tabular}

Médias seguidas pela mesma letra, na coluna, não diferem entre si, pelo teste Tukey, a $5 \%$. ${ }^{\text {ns }}$ Não significativo. * e $* *$ Significativo a $5 \%$ e $1 \%$, respectivamente, pelo teste $\mathrm{F}$. 
Tabela 3. Número de vagens planta ${ }^{-1}$ de feijoeiro, em função de cultivares e época de aplicação de regulador vegetal (desdobramento das interações significativas cultivares x épocas) (Selvíria, MS, 2007).

\begin{tabular}{lcc}
\hline \multirow{2}{*}{ Cultivares } & \multicolumn{2}{c}{ Época de aplicação } \\
\cline { 2 - 3 } & Vegetativa (29 DAE) & Reprodutiva (R5) \\
\hline IAC Apuã & 10,2 a B & 11,5 a A \\
Carioca Precoce & 10,8 a A & 10,4 b A \\
\hline DMS & \multicolumn{3}{c}{0,673} \\
\hline
\end{tabular}

Médias seguidas pela mesma letra não diferem entre si, pelo teste Tukey, a 5\% (letra minúscula: comparação na coluna; letra maiúscula: comparação na linha).

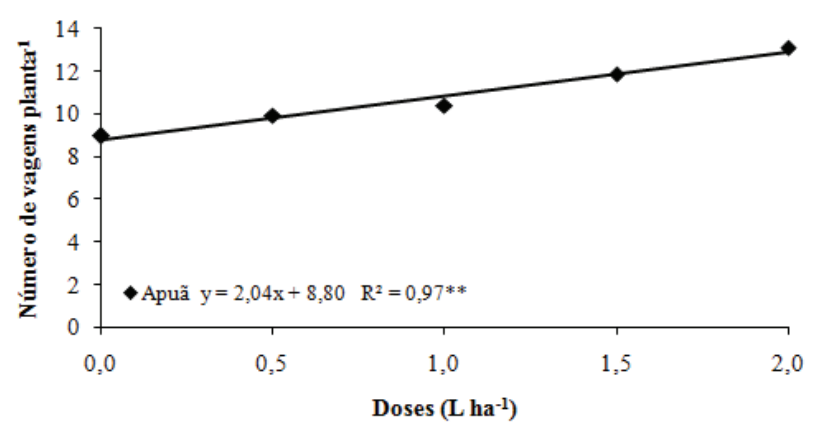

Figura 1. Número de vagens planta ${ }^{-1}$ de feijão da cultivar IAC Apuã (desdobramento das interações significativas doses x cultivares), em função da aplicação de regulador vegetal (Selvíria, MS, 2007).

Há de se considerar, também, que o ácido indolbutírico presente no regulador vegetal utilizado participa do crescimento, principalmente pelo alongamento celular; retarda a abscisão de flores; e estimula o pegamento de flores sem fecundação (Andrei 2005), o que pode ter ocorrido com a aplicação do regulador vegetal em R5, para esta cultivar.

Vieira (2001), estudando diferentes concentrações de Stimulate ${ }^{\circledR}$ aplicado a sementes de feijão cultivar Carioca, verificou efeito quadrático destas concentrações, sendo que o número máximo de vagens por planta alcançado foi 25,1 vagens, para a concentração de $2,4 \mathrm{~mL}$, com posterior redução, a partir desta concentração. Já Castro et al. (2004), avaliando o efeito de aplicações foliares em feijão, aos 15 e 30 dias após a germinação, e aplicação de

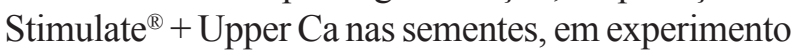
realizado em vaso, constataram que os tratamentos não afetaram, significativamente, o número de vagens por planta. No entanto, Oliveira et al. (1998), avaliando a aplicação de Stimulate $^{\circledR}$ em diversas épocas, associadas ou não à aplicação do produto nas sementes de feijão cultivar Carioca, constataram efeito significativo no número de vagens por planta somente quando realizado o tratamento das sementes e, quando foi realizada aplicação foliar, não puderam associar o efeito da giberelina ou citocinina à produção de vagens de feijão.

As diferentes doses e épocas de aplicação do regulador vegetal testadas não influenciaram o número de grãos por vagem e a massa de 100 grãos, apresentando diferenças significativas somente entre as cultivares.

Pode-se constatar que a cultivar Carioca Precoce apresentou o maior número de grãos por vagem e a maior massa de 100 grãos, em relação ao IAC Apuã (Tabela 2). Contudo, Alleoni et al. (2000), ao avaliarem o número de grãos/vagem da cultura de feijão, não constataram diferença significativa entre os tratamentos e a testemunha. Entretanto, estes afirmam que ocorreu incremento de $1,7 \%$, quando foi realizada aplicação única, na dose de $750 \mathrm{~mL} \mathrm{ha}^{-1}$ via foliar, em relação à testemunha. Com relação à massa de 1.000 grãos, os mesmos autores observaram que houve diferença significativa entre o tratamento que recebeu a dose de $250 \mathrm{~mL} \mathrm{ha}^{-1}$ do regulador vegetal nas sementes e $750 \mathrm{~mL} \mathrm{ha}^{-1}$ via foliar, em aplicação única, em relação à testemunha.

Ao avaliar o número de grãos por planta, pode-se constatar que não houve diferenças significativas entre as cultivares, porém, as doses e épocas de aplicação do regulador vegetal apresentaram efeitos significativos (Tabela 2), sendo que o efeito da dose não é dependente da época. O número de grãos por planta aumentou linearmente, mediante os acréscimos das doses do regulador vegetal (Figura 2), e a melhor época de aplicação se dá no estádio (R5) (Tabela 2).

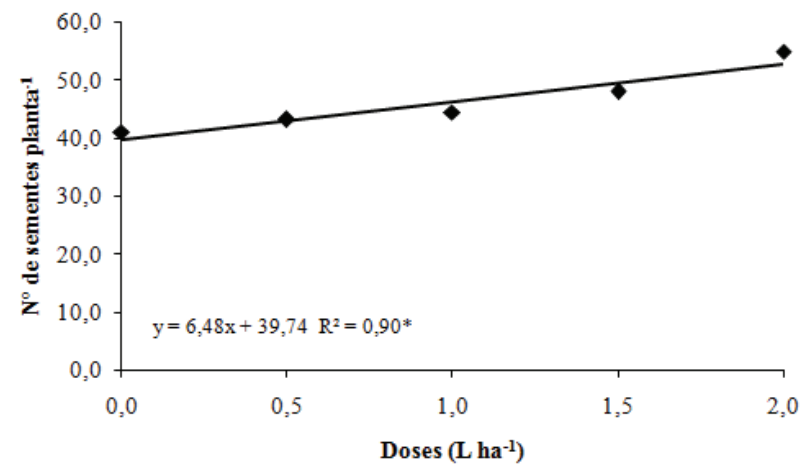

Figura 2. Número de grãos planta ${ }^{-1}$ de feijão, cultivares IAC Apuã e Carioca Precoce, em função do efeito da aplicação de regulador vegetal (Selvíria, MS, 2007). 
Para Taiz \& Zeiger (2004), os hormônios e nutrientes são substâncias que controlam a relação fonte/dreno de assimilados em plantas. O maior número de grãos por planta, alcançado no estádio reprodutivo (R5), pode ser explicado por esta relação. Provavelmente, quando o regulador vegetal é aplicado neste estádio fenológico, serve como dreno para a liberação e/ou remobilização de carboidratos, originando grãos verdadeiros e refletindo, positivamente, na produtividade.

Para a produtividade de grãos, ocorreram diferenças significativas entre as cultivares, doses e épocas de aplicação do regulador vegetal. A produtividade de grãos de feijão aumentou linearmente (Figura 3), mediante o aumento das doses do regulador vegetal, obtendo-se, na dose máxima, o valor de $2.414 \mathrm{~kg} \mathrm{ha}^{-1}$. Dentre as cultivares, a mais produtiva foi a Carioca Precoce e, quanto à época de aplicação, o estádio reprodutivo (R5) proporcionou melhor produtividade, em média $822 \mathrm{~kg} \mathrm{ha}^{-1}$ a mais do que quando o produto foi aplicado no estádio vegetativo (V4) (Tabela 2).

Quando o ácido giberélico é aplicado antes do florescimento, este induz a um crescimento vegetativo intenso, em diversas culturas, o qual é maior do que o necessário para a máxima produtividade, e, neste caso, nutrientes e fotossintetizados são direcionados ao crescimento vegetativo, em detrimento ao desenvolvimento de estruturas reprodutivas (Leite et al. 2003). Talvez seja por este motivo que a aplicação no estádio reprodutivo (R5) tenha sido a que melhor respondeu à aplicação do regulador vegetal, tanto para número de grãos por planta quanto para a produtividade, porque, de acordo com Rodrigues \& Leite (2004), a aplicação de giberelina pode estimular

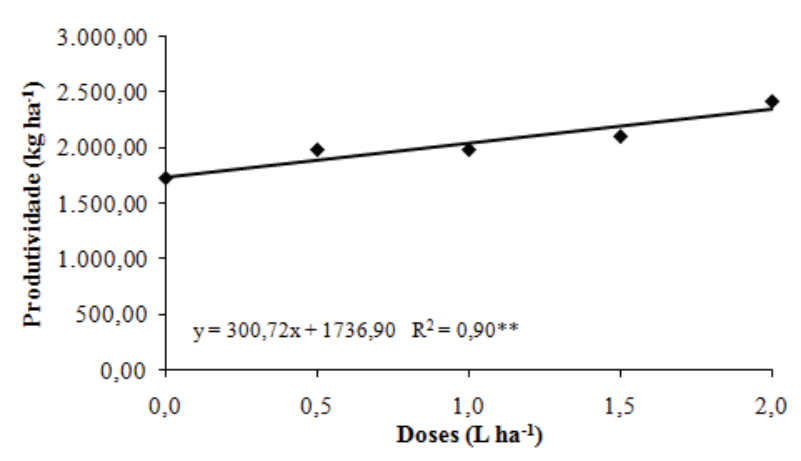

Figura 3. Produtividade de grãos de feijão $\left(\mathrm{kg} \mathrm{ha}^{-1}\right)$, cultivar IAC Apuã e Carioca Precoce, em função do efeito da aplicação de doses de regulador vegetal (Selvíria, MS, 2007). o pegamento e o crescimento de frutos de diversas espécies. No entanto, resultados diferentes foram encontrados por Oliveira et al. (1998), estudando diferentes tratamentos com regulador vegetal, nos quais verificaram que o produto não proporcionou efeitos significativos sobre a produtividade de feijão.

Já Cobucci et al. (2005), em experimento utilizando sementes tratadas com micronutrientes Co e Mo $(0,15 \mathrm{~L} / 50 \mathrm{~kg}$ de sementes $)$ e Stimulate ${ }^{\circledR}$ $(0,25 \mathrm{~L} / 50 \mathrm{~kg}$ de sementes $)$, e realizando aplicação via foliar do Stimulate ${ }^{\circledR}$, na dose de $0,25 \mathrm{~L} \mathrm{ha}^{-1}$, em dois estádios fenológicos (V4 e R5), constataram que houve aumento significativo sobre a produtividade do feijão apenas quando o produto foi aplicado em R5. Esta informação sobre a época de aplicação corrobora o observado no presente trabalho, sendo o estádio R5 o melhor período para aplicação do regulador vegetal.

\section{CONCLUSÕES}

1. Características vegetativas como altura das plantas de feijão, altura de inserção da primeira vagem, número de grãos por vagem e massa de 100 grãos não foram alteradas com a aplicação do regulador de crescimento.

2. A aplicação do regulador de crescimento no estádio reprodutivo (R5) aumentou o número de grãos por planta e a produtividade de grãos das cultivares de feijoeiro Carioca Precoce e IAC Apuã.

3. A dose de $2 \mathrm{~L} \mathrm{ha}^{-1}$ foi a mais efetiva para o aumento no número de grãos por planta e na produtividade de grãos.

\section{REFERÊNCIAS}

ALBUQUERQUE, R. C. et al. Efeitos do bioestimulante Stimulate ${ }^{\circledR}$ em sementes pré-embebidas de mamona (Ricinus communis L.). In: CONGRESSO BRASILEIRO DE MAMONA: ENERGIA E SUSTENTABILIDADE, 1., 2004, Campina Grande. Anais... Campina Grande: Embrapa Algodão, 2004. 1 CD-ROM.

ALLEONI, F.; BOSQUEIRO, M.; ROSSI, M. Efeito dos reguladores vegetais de Stimulate no desenvolvimento e produtividade do feijoeiro (Phaseolus vulgaris). Ciências Exatas e da Terra, Ciências Agrárias e Engenharias, Ponta Grossa, v. 6, n. 1, p. 23-35, 2000.

AMBROSANO, E. J. et al. Leguminosas e oleaginosas. In: RAIJ, V. B. et al. Recomendações de adubação e calagem para o Estado de São Paulo. 2. ed. Campinas: IAC, 1997. p. 189-203. (Boletim técnico, 100). 
ANDREI, E. (Coord.). Compêndio de defensivos agrícolas: guia prático de produtos fitossanitários para uso agrícola. 7. ed. São Paulo: Organizações Andrei, 2005.

BERTOLIN, D. C. et al. Aumento da produtividade de soja com a aplicação de bioestimulantes. Bragantia, Campinas, v. 69 , n. 2 , p. $339-347,2010$.

CASILlAS, V. J. C. et al. Análisis cuantitativo de la aplicacion de cuatro bioestimulants en el cultivo del rabano (Raphanus sativus L.). Acta Agronomica, Palmira, v. 36, n. 2, p. 185-195, 1986.

CASTRO, P. R. C. et al. Ação de bioestimulantes em feijoeiro (Phaseolus vulgaris CV. IAC - Carioca Tybatã). Revista de Agricultura, Piracicaba, v. 79, n. 2, p. 215-226, 2004.

COBUCCI, T.; CURUCK, F. J; SILVA, J. G. da. Resposta do feijoeiro (Phaseolus vulgaris L.) às aplicações de bioestimulante e complexos nutritivos. Goiânia: Conafe, 2005.

DARIO, G. J. A. et al. Influência do uso de fitorregulador no crescimento da soja. Revista da Faculdade de Zootecnia, Veterinária e Agronomia, Uruguaiana, v. 12, n. 1, p. 63-70, 2005.

DOURADO NETO, D. et al. Aplicação e influência do fitorregulador no crescimento das plantas de milho. Revista da Faculdade de Zootecnia, Veterinária e Agronomia, Uruguaiana, v. 11, n. 1, p. 93-102, 2004.

EMPRESA BRASILEIRA DE PESQUISA AGROPECUÁRIA (Embrapa). Centro Nacional de Pesquisa de Solos. Sistema brasileiro de classificação dos solos. Rio de Janeiro: Embrapa SPI/CNPS, 1999.

FANCELLI, A. L.; DOURADO-NETO, D. Feijão: ecofisiologia e fenologia. In: FANCELLI, A. L.; DOURADO-NETO, D. (Eds.). Produção de feijão. Piracicaba: ESALQ, 2007. p. 23-48.

LANA, A. M. Q. et al. Aplicação de reguladores de crescimento na cultura do feijoeiro. Bioscience Journal, Uberlândia, v. 25, n. 1, p. 13-20, 2009.

LEITE, V. M.; ROSOLEM, C. A.; RODRIGUES, J. D. Gibberellin and cytokinin effects on soybean growth. Scientia Agricola, Piracicaba, v. 60, n. 3, p. 537-541, 2003.
LIMA, M. M. et al. Níveis de adubação nitrogenada e bioestimulante na produção e qualidade do algodão BRS verde. Revista Brasileira de Engenharia Agrícola e Ambiental, Campina Grande, v. 10, n. 3, p. 619-623, 2006.

MAEDA, S.; MENDONÇA, A. L. Época de semeadura: a cultura do feijão no Mato Grosso do Sul. Dourados: Embrapa, 1990.

OLIVEIRA, R. F. de; PACE, L.; ROSOlEM, C. A. Produção e estado nutricional do feijoeiro em função da aplicação de um promotor de crescimento. Cientifica, São Paulo, v. 26, n. 1/2, p. 203-212, 1998.

RAIJ, B. V. et al. Análise química para avaliação da fertilidade de solos tropicais. Campinas: Instituto Agronômico, 2001.

RODRIGUES, T. J. D.; LEITE, I. C. Giberelinas. In: RODRIGUES, T. J. D.; LEITE, I. C. Fisiologia vegetal: hormônios das plantas. Jaboticabal: Funep, 2004. p. 19-38.

TAIZ, L.; ZEIGER, E. Fisiologia vegetal. 3. ed. Porto Alegre: Artmed, 2004.

VIEIRA, E. L. Ação de bioestimulante na germinação de sementes, vigor de plântulas, crescimento radicular e produtividade de soja (Glycine max (L.) Merril), feijoeiro (Phaseolus vulgaris L.) e arroz (Oryza sativa L.). 2001. 122 f. Tese (Doutorado em Agronomia)-Escola Superior de Agricultura "Luiz de Queiroz", Universidade de São Paulo, Piracicaba, 2001.

VIEIRA, E. L.; CASTRO, P. R. C. Ação de bioestimulante na cultura da soja (Glycine max (L.) Merrill). Cosmópolis: Stoller do Brasil, 2004.

VIEIRA, E. L.; CASTRO, P. R. C. Ação de bioestimulante na germinação de sementes, vigor de plântulas, crescimento radicular e produtividade de soja. Revista Brasileira de Sementes, Brasília, DF, v. 23, n. 2, p. 222-228, 2001.

VIEIRA, E. L.; CASTRO, P. R. C. Ação de Stimulate no desenvolvimento inicial de plantas de algodoeiro (Gossypium hirsutum L.). Piracicaba: USP, 2002.

WEAVER, R. J. Plant growth substances in agriculture. San Francisco: W. H. Freeman, 1972. 